\title{
High-temperature Static Strain Langasite SAWR Sensor: Temperature Compensation and Numerical Calibration for Direct Strain Reading
}

\author{
Anin Maskay ${ }^{\mathrm{a}, \mathrm{b}}$ and Mauricio Pereira da Cunha ${ }^{\mathrm{a}, \mathrm{b}}$ \\ ${ }^{a}$ Laboratory of Surface Science and Technology, University of Maine, 5708 ESRB-Barrows Hall, Orono, ME 04469, USA \\ ${ }^{b}$ Dept. of Electrical and Computer Engineering, University of Maine, 5708 ESRB-Barrows Hall, Orono, ME 04469, USA
}

E-mail: anin.maskay@maine.edu

\section{Introduction}

High-temperature harsh-environment strain sensors are needed for industrial process monitoring and control, fault detection, structural health monitoring applications, in power plant environments, steel and refractory material manufacturing, aerospace, and defense [1]-[4]. At temperatures above a few hundred degree Celsius and under the harsh-environments encountered in the aforementioned applications, strain sensing poses significant challenges. Among these one can list: (i) the resilience of the sensor itself; (ii) difficulty in attaching the sensor to the part to be monitored due to mismatch between the coefficient of thermal expansion (CTE) of the sensor material and the CTE of the test part; (iii) high-temperature harsh-environment sensor packaging; and (iv) quick variations in environmental conditions (e.g., temperature, pressure, and vibration) [5], [6].

Wired strain gauge, which operates based on gauge resistance as a function of strain, is one of the hightemperature static strain sensor technologies available and reported to operate at temperatures in excess of $1300^{\circ} \mathrm{C}$ [7]. These sensors are made of high-temperature capable materials that are either welded to the test part by flame spraying technique or attached by epoxying the sensor using a ceramic-based cement. Current limitations in wired strain gauge performance and applications are related to: (i) sensor wiring; (ii) bulky harsh-environment attachment and housing (such as fiberglass insulation or ceramic braiding or a metal jacket); (iii) drift in response due to oxidation; (iv) accuracy and precision [8].

Commercially available optical strain sensors use Fiber Bragg Grating technology (FBG) and target operation up to $1000^{\circ} \mathrm{C}$ for oil and gas pipeline leakage, structural health, and security monitoring [9]. These sensors can be lightweight and small, but may drift due to changes in fiber doping profile at high-temperature, harsh-environment. In addition, they suffer the interference of deposits in lenses or interfaces, and may require special housing and packaging for access in high-temperature operation conditions, which adds volume to the sensor assembly and complicates instrumentation [10].

Capacitive micro-electro-mechanical-systems (MEMS) static pressure sensors implemented as individual devices or as thin films deposited directly on the part to be monitored have been explored in the temperature range of $600^{\circ} \mathrm{C}$ to $1100^{\circ} \mathrm{C}$ [8], [11]. The devices have been fabricated using wide band-gap materials, such as silicon carbide (SiC) for up to $600^{\circ} \mathrm{C}$, and high-temperature substrates, such as alumina, for thin film deposition up to $1100^{\circ} \mathrm{C}$. MEMS based sensors often require signal conditioning and amplification through embedded integrated circuitry, which translates into increased complexity, size, and weight. The need for battery or some sort of power source often implies the necessity of regular maintenance, which increases cost and is a complication for high-temperature operation of MEMS-based harsh-environment static strain sensors.

Overall, a limiting aspect of wired and optical strain sensor technologies is the need for cable routing and housing, which: (i) increases the risk of failure; (ii) adds size and weight; (iii) complicates installation, often becoming intrusive on the targeted part or system to be monitored; and (iv) increases the sensor system implementation and maintenance costs. 
Numerical modeling, in particular, finite element method (FEM), is an alternate approach for inferring the strain values of a part or equipment at high-temperature harsh-environment conditions. In this work, this technique has been used to calibrate and verify sensor operation at high-temperature.

For the reasons discussed so far, sensors that are small, robust, allow for flexible packaging, and which offer the possibility of operating wirelessly and battery-free are very attractive for harsh-environment applications. Surface acoustic wave (SAW) sensors have the potential to address all these requirements due to their robustness, simplicity of packaging, ease and cost efficiency of use [3], [5], [6], [12]. In particular, the wireless sensing and battery-free operation capabilities are extremely attractive for harsh-environment operation, since they diminish or eliminate the need for maintenance; allow operation at temperatures where no battery or energy scavenging method is feasible; dispenses additional circuitry at the sensor level, thus also reducing bulkiness, and improves reliability. SAW pressure sensor technology [13], [14] has been more recently adapted and used as: torque and pressure sensors in automotive applications [15]; as strain sensors in industrial harsh-environment monitoring [16]; and structural health monitoring [3].

Common piezoelectric crystal substrates considered for SAW harsh-environment applications are [12]: quartz (QTZ, $\left.\mathrm{SiO}_{2}\right)$; lithium niobate $\left(\mathrm{LNO}, \mathrm{LiNbO}_{3}\right)$; gallium orthhophosphate $\left(\mathrm{GPO}, \mathrm{GaPO}_{4}\right)$; the langasite family of crystals (LGX), which refers to langasite (LGS, $\mathrm{La}_{3} \mathrm{Ga}_{5} \mathrm{SiO} 14$ ), langatate (LGT, La3Ga5.5Ta0.5O14), and langanite (LGN, La3Ga5.5Nb0.5O14); calcium gallium germanate, langasite isomorph crystals, such as $\mathrm{Ca}_{3} \mathrm{NbGa}_{3} \mathrm{Si}_{2} \mathrm{O}_{14}$ (CNGS), $\mathrm{Ca}_{3} \mathrm{TaGa}_{3} \mathrm{Si}_{2} \mathrm{O}_{14}$ (CTGS), $\mathrm{Sr}_{3} \mathrm{NbGa}_{3} \mathrm{Si}_{2} \mathrm{O}_{14}$ (SNGS), and $\mathrm{Sr}_{3} \mathrm{TaGa}_{3} \mathrm{Si}_{2} \mathrm{O}_{14}$ (STGS), and piezoelectric films

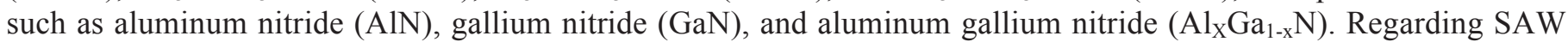
strain sensors, packaging [6] and calibration [17] using quartz AT-X sensors have been investigated up to $100^{\circ} \mathrm{C}$; LGS SAW strain sensors for fastener failure detection in aircrafts using orthogonal frequency coding reflectors have been discussed in [3] up to $100^{\circ} \mathrm{C}$, and more recently the frequency response of LGS crystals to crystal deformation up to $500^{\circ} \mathrm{C}$ has been reported in [18]. At temperatures higher than $100^{\circ} \mathrm{C}$, multiple issues pose substantial challenges for harsh-environment strain sensor implementation: (i) sensor calibration; (ii) device integrity; (iii) mounting and packaging; (iv) adhesive failure; (v) hysteretic sensor response due to adhesive \& packaging variation with temperature and time; (vi) temperature-strain cross-sensitivity.

This paper presents temperature-compensated surface acoustic resonator (SAWR) strain sensors calibrated at hightemperature using a numerical FEM model, thus allowing direct strain reading. Due to the lack of reliable hightemperature commercial static strain gauge for operation up to $400^{\circ} \mathrm{C}$, a numerical FEM model was created using the FEM software package, Abaqus (Dassault Systèmes, Waltham, MA). Measurements employing a commercial room temperature strain sensor and cyanoacrylate adhesive were used to validate the FEM model such that the correlation between predicted and measured data around room temperature approached unity. At high-temperatures, the SAWR strain sensor was attached to a constant stress beam employing an $\mathrm{Al}_{2} \mathrm{O}_{3}$ based high-temperature epoxy. The FEM model validated at room temperature was then extended to consider high-temperature material constants and used as a reference to perform SAWR strain sensor calibration up to $114 \mu \varepsilon$ and at temperatures up to $400^{\circ} \mathrm{C}$. The sensors were fabricated using LGS, thus building up on the previously successful work with this commercially available crystal and orientation [12]. Langasite was selected due to the crystal's proven stability at the temperature values targeted in this work, and also for temperatures beyond $400^{\circ} \mathrm{C}$, thus allowing for future developments at even higher temperatures. Due to the sensor response to temperature, a multi-sensing, temperature compensation approach consisting of a SAWR strain sensor and a SAWR temperature sensor was employed to mitigate the cross-sensitivity response due to eventual temperature variations at the targeted high-temperatures.

The architecture of the SAWR and its operating principle as a strain sensor are explained in Section 2. Section 3 discusses the stress beam used in this work as well as the rationale and validation procedure of the FEM model at room temperature. The need and implementation of temperature compensation scheme used in this work and the modifications of the FEM modeling for operation at high-temperatures are discussed in Section 4. Section 5 describes the experimental setup and test procedures for the room temperature and the high-temperature strain tests performed. 
Section 6 discusses the SAWR strain sensor test results at room temperature, $300^{\circ} \mathrm{C}$, and $400^{\circ} \mathrm{C}$. Section 7 concludes the paper.

\section{Device Fabrication and Operation}

\subsection{Device Fabrication}

The type of thin film electrode selected to fabricate the LGS SAWR sensor is critical for high-temperature harshenvironment operation. From the different types of thin film electrode structures developed by the University of Maine (UMaine) group for high-temperature wired and wireless sensor applications [12], [19]-[23], the multilayered $\mathrm{Pt}-\mathrm{Ni} \mid \mathrm{Pt}-\mathrm{Zr}$ film has been selected in this work for the fabricated strain sensors, due to the observed good performance at high-temperature and sensor stability.

One-port LGS SAWR sensors were designed and fabricated along LGS Euler angles $\left(0^{\circ}, 138.5^{\circ}, 26.7^{\circ}\right)$ with 161 interdigitated transducer (IDT) electrodes, mark-to-space ratio 1:1; acoustic aperture of 51 wavelengths $(\lambda)$; and opencircuited grating reflectors with 822 electrodes each designed to operate at $195 \mathrm{MHz}$. At this operating frequency, the designed device is approximately $4 \mathrm{~mm}$ by $9 \mathrm{~mm}$, which was considered an appropriate size to mount on the constant stress beam, and also comparable in size with the commercial room temperature static strain gauge $(4.8 \mathrm{~mm} \times 6.9 \mathrm{~mm})$ used in this work for validation of the FEM model. In addition, UMaine had prior experience with $195 \mathrm{MHz}$ LGS sensors as temperature sensors [12], [19]-[23] and as pressure sensors [24], which was used as baseline comparison for the quality of the devices fabricated. The thin film electrode structure consists of a $50 \mathrm{~nm} \mathrm{Al}_{2} \mathrm{O}_{3}$ thick interfacial layer deposited using atomic layer deposition (ALD) on top of the entire LGS substrate, followed by $10 \mathrm{~nm}$ thick zirconium ( $\mathrm{Zr}$ ) adhesion layer, and the multilayered $\mathrm{Pt}-\mathrm{Ni} \mid \mathrm{Pt}-\mathrm{Zr}$ film, which consists of $15 \mathrm{~nm}$ co-deposited Pt-Ni interlaced with $15 \mathrm{~nm}$ of co-deposited Pt-Zr, five layers of each, to a total of $150 \mathrm{~nm}$. A $50 \mathrm{~nm} \mathrm{ALD} \mathrm{Al}_{2} \mathrm{O}_{3}$ insulating capping layer is then grown over the entire device, and acts as a protective cover. On top of the bondpad region, a thin film consisting of $50 \mathrm{~nm} \mathrm{Zr}$ followed by $50 \mathrm{~nm}$ thin film Pt is patterned, followed by a thick film Pt conductive paste patterned by screen printing [12]. The thick paste allows capacitive coupling access of the device and improves bonding performance at high-temperature.

Figure 1 shows a photograph of the fabricated SAWR sensor with a micrograph (Fig. 1 inset) illustrating the transducer pattern of the fabricated SAWR sensor. The IDT and grating reflector electrode widths are $3.5 \mu \mathrm{m}$, the mark-to-space ratio is $1: 1$, and thus the periodicity, $p=7 \mu \mathrm{m}$, and wavelength, $\lambda=14 \mu \mathrm{m}$. The SAWR resonant frequency can be calculated as, where is the SAW velocity in the structure [17]. Using the surface acoustic wave velocity for LGS $\left(0^{\circ}, 138.5^{\circ}, 26.7^{\circ}\right)$ as $2738 \mathrm{~m} / \mathrm{s}$ [25] and the patterned periodicity of $7 \mu \mathrm{m}$, the designed SAWR resonant frequency calculated using the aforementioned relationship is $195.6 \mathrm{MHz}$. The fabricated SAWRs had measured resonant frequencies between 195.2 MHz and $195.8 \mathrm{MHz}$, therefore consistent with the predicted value considering the fabrication process spreading and, in particular, the complex film structure, which consists of adhesion, interfacial, electrode, and capping layers previously detailed.

\subsection{Device Operation}

Static bias (strain/pressure) on the SAWR deforms the device, altering the effective material properties where the acoustic wave propagates, and slightly modifying the effective pitch of the periodic transducers and reflecting structures. These changes lead to a frequency shift $(\Delta f)$ of the SAWR resonant frequency. Therefore, $\Delta f$ can be related to strain on the sensor due the applied stress. Upon calibration, the measured $\Delta f$ is translated into a static strain reading.

Sensitivity of a SAWR strain sensor depends on its placement and relative alignment to the part being tested. Moulzolf et al. [24] tested different alignments of LGS $\left(0^{\circ}, 138.5^{\circ}, 26.7^{\circ}\right)$ SAW pressure sensors using static test beams and concluded that the largest pressure sensitivity was observed when the sensor was placed with the SAW 
propagation direction parallel to the longitudinal axis of the beam. This mounting condition, also consistent with strain sensor operation on $36^{\circ}$ AT Quartz [17], was used in this work to maximize strain sensitivity.

\section{The High-temperature Constant Stress Beam and The FEM Model Validation at Room Temperature}

\subsection{Constant Stress Beam}

A constant stress beam is ideal for accurate strain gauge calibration as per American Society for Testing and Materials (ASTM) Standard E251-92 [26], and thus was used for the strain tests measurements reported in this work at room temperature and high-temperatures. The stress along a particular section of the beam can be made constant by varying either the width or the thickness of the beam with length. Machining a beam with varying thicknesses, $t$, to maintain a constant stress is difficult and usually not practical due to the reduction of the transversal dimension, decrease in the maximum transversal shear stress limit, and required precision of beam thickness. By varying the width, $b$, of the beam as a function of the distance from the clamped left end (Fig. 2), according to $b(x)=K x$, where $K$

is a proportionality constant $(K=b(0) / l)$, while keeping the thickness, $t$, constant, the stress on the beam can be expressed as [27]

$$
\sigma x=6 P x b(x) t 2=6 P x K x+2=6 P K t 2=\text { constant },
$$

where $\sigma x=$ Stress as a function of position,

$x=$ Distance from the clamped end,

$P=$ Force applied.

Environetix Technologies Corporation generously lent a constant stress beam (constant stress section of $35 \mathrm{~mm}$ by $40 \mathrm{~mm}$ ) machined from Inconel-625 (Fig. 3, top). Inconel-625 is a relatively stable alloy with a melting point of $1350^{\circ} \mathrm{C}[28]$, thus ideal for the high-temperature tests targeted in this work.

\subsection{FEM Modeling and Validation at Room Temperature}

A commercial strain gauge from Micro-Measurements, part number CEA-00-032UW (Micro-Measurements, Wendell, NC), with $350 \Omega$ nominal resistance, $1.4 \pm 0.2$ gauge factor, and maximum operating temperature of $175^{\circ} \mathrm{C}$ [29] was selected to validate the FEM software model at room temperature. Comparisons between measured and simulated results were used to validate the FEM model, as shown in Section 6.1, prior to its usage as strain reference for the SAWR sensor calibration at high-temperatures.

A three-dimensional drawing of the constant stress beam was created in AutoCAD (Autodesk, San Rafael, CA), a computer-aided design and drafting software. The drawing was imported into Abaqus and the nominal material properties of Inconel- 625 at $24^{\circ} \mathrm{C}$ were used, namely: density, Young's modulus, and Poisson's ratio given in [28]. The constant stress beam clamped at one end was simulated in Abaqus to verify constant stress operation. The simulated structure was meshed using tetrahedral mesh elements with seed sizes of 0.002 . A fixed boundary condition was applied to the clamped end of the model to constrain translational displacements and rotations at that end. Abaqus general static stress analysis using concentrated force loads applied normal to the plane of the beam, is representative of the experimental loading conditions, and was implemented to extract strain fields on the beam for 14 selected static load values between 10 grams and 510 grams. The aforementioned entries for constant stress beam in Abaqus, including the imposed boundary conditions and the loading, are referred to in this work as the FEM model. Figure 3 bottom depicts the beam structure under the static load condition and the FEM simulation results, which reveal that the thinner part in the middle, colored in red, is undergoing constant stress within $\pm 2.5 \%$ over the entire constant stress region. 


\section{Temperature Compensation and FEM Modeling at High-temperature}

\subsection{Additional SAWR for temperature compensation}

The SAWR strain sensor used in this work is sensitive to temperature variations [23], which can affect hightemperature strain measurements. Therefore, a temperature compensation scheme must be used to deal with straintemperature cross-sensitivity, and in this work a second SAWR sensor was used for temperature reference.

Temperature sensitivity of the SAWR strain sensor was evaluated in a Thermolyne Model 48000 (Thermo Fisher Scientific, Inc., Waltham, MA) box furnace. The sensor was epoxied to the test beam employing the attachment procedure described in the high-temperature experimental setup Section 5.2. The SAW frequency was tracked using an Agilent E5071C VNA (Agilent Technologies Inc., Santa Clara, CA). The mean and standard deviation of SAW frequency variation measured at $24^{\circ} \mathrm{C}, 200^{\circ} \mathrm{C}, 300^{\circ} \mathrm{C}, 400^{\circ} \mathrm{C}$, and $500^{\circ} \mathrm{C}$ through ten VNA sweeps at each temperature, and a corresponding second order polynomial fitting to the data points are shown in Fig. 4.

Based on these measurements, the second order polynomial fitting for the SAW frequency-temperature relation is given by

$$
f S \text {, beam unloadedTemperature }=-9.42 \times 10-3 \mathrm{~T} 2-0.102 \mathrm{~T}+7.87[\mathrm{kHz}]
$$

where $f S$, beam unloadedTemperature represents the frequency variation due to temperature only of the unstrained epoxied strain sensor, with $f_{o}=195.2 \mathrm{MHz}$ at $T=24^{\circ} \mathrm{C}$.

Between $300^{\circ} \mathrm{C}$ and $400^{\circ} \mathrm{C}$, the temperature sensitivity of the SAWR strain sensor is about $-6.7 \mathrm{kHz} /{ }^{\circ} \mathrm{C}$. Note that the temperature in the furnace can vary up to $\pm 1.5^{\circ}$ at $300^{\circ} \mathrm{C}$ and $400^{\circ} \mathrm{C}$ due to the furnace's proportional-integralderivative (PID) controller. At $300^{\circ} \mathrm{C}$, the standard deviation in frequency shift is $\pm 250 \mathrm{~Hz}$, which increases to $\pm 382 \mathrm{~Hz}$ at $400^{\circ} \mathrm{C}$. Frequency variation values of this magnitude are relatively significant with respect to those due to the targeted strain variations to be measured and cannot be ignored. Thus, a multi-sensor temperature compensation strategy had to be implemented to address temperature fluctuations. The temperature compensation approach relies on the following assumptions: i.) Both sensors have the same temperature dependencies; ii.) Both sensors are interrogated at the same time and are subject to the same temperature; and (iii) The temperature sensor is insensitive to strain variations.

Defining the frequency shift in the strain sensor $\left(\Delta f_{S}\right)$, which accounts for frequency variation due to both temperature and strain, as

$$
f S=f S, \text { beam strained }-f S, \text { beam unloaded }
$$

and the frequency shift in the free-to-slide temperature sensor $\left(\Delta f_{T}\right)$, which accounts for frequency variation due to temperature only, as

$$
f T=f T \text {, beam strained }-f T, \text { beam unloaded }
$$

where $f S$, beam strained and $f S$,beam unloaded represent the measured strained and unstrained resonant frequencies for the strain sensor, respectively, and $f T$, beam strained and $f T$, beam unloaded are, respectively, the measured strained and unstrained resonant frequencies for the temperature sensor. The shift due to strain alone, $\Delta f_{\text {Strain }}$, can be calculated from the measured frequency variations by 


\subsection{FEM Model at High-temperature}

The mechanical properties of Inconel-625 vary significantly from room temperature to high-temperature, and these variations must be considered in the FEM model to properly predict the response of the beam to the applied static stresses at high-temperatures. For example, between room temperature and $400{ }^{\circ} \mathrm{C}$ the Poisson's ratio varies $6 \%$, and the Young's modulus, $10 \%$. Density also varies by $1.5 \%$ due to the material expansion.

Figure 5a shows polynomial curve fitting for the fractional variation data provided in [28] of Inconel-625 Young's modulus $(\% Y)$ (broken curve) and Poisson's ratio (\% ) (solid curve). Figure 5b shows polynomial fitting for the temperature dependent CTE () data obtained from [28], which is used to account for density variation with temperature.

The extracted coefficients for in Young modulus $(\%)$ and Poisson ratio $(\%)$ fractional variations as functions of temperature $(T)$ are given as:

$$
\begin{aligned}
& \% Y=-2.84 \times 10-8 \mathrm{T3}+ \\
& 1.99 \times 10-5 \mathrm{~T} 2-0.030 \mathrm{~T}+0.773 \quad[\%] \\
& \%=-1.09 \times 10-12 \mathrm{~T} 5+2.05 \times 10-9 \mathrm{~T} 4 \\
& -1.28 \times 10-6 \mathrm{~T} 3+3.27 \times 10-4 \mathrm{~T} 2 \\
& -0.016 T+0.226[\%]
\end{aligned}
$$

with $Y=207.5[\mathrm{GPa}]$ and $v=0.278$ [dimensionless] at $T=21^{\circ} \mathrm{C}$.

The fitted CTE from Fig. $5 \mathrm{~b}$ as a function of temperature $(T)$ is given by

$$
\begin{aligned}
=-2.50 \times 10-11 \mathrm{~T} 4 & +5.56 \times 10-8 \mathrm{T3}+ \\
+ & 2.43 \times 10-5 \mathrm{~T} 2-0.007 \mathrm{~T}+12.3\left[\mu \mathrm{m} /\left(\mu \mathrm{m}^{\circ} \mathrm{C}\right)\right]
\end{aligned}
$$

This fitted equation calculated from the data points given in [28] applies for $T$ in ${ }^{\circ} \mathrm{C}$ and in the range of $93^{\circ} \mathrm{C}$ to $927^{\circ} \mathrm{C}$.

The temperature dependent material data discussed above was used in the FEM model at high-temperatures, and the FEM model was used for the calibration of the SAWR sensor. The simulated strain values at the targeted temperatures of $24^{\circ} \mathrm{C}, 300^{\circ} \mathrm{C}$, and $400^{\circ} \mathrm{C}$ are shown in Fig. 6 as a function of the mass loading the beam. The same

mass load values were used at high-temperatures to directly translate the measured temperature compensated frequency shift of the SAWR strain sensor $\left(\Delta f_{\text {Strain }}\right)$ into strain.

\section{Experimental Setup}

\subsection{Room Temperature Strain Testing Setup}

The block diagram and complete room temperature test setup are shown in Fig. 7. The commercial strain gauge, introduced in Section 3.2 to validate the FEM model, was also used to calibrate the SAWR sensor at room 
temperature, thus translating the measured SAW frequency variation into strain. A $195 \mathrm{MHz}, 4 \mathrm{~mm} \times 9 \mathrm{~mm}$ SAWR sensor was placed next to the $4.8 \mathrm{~mm} \times 6.9 \mathrm{~mm}$ commercial strain gauge, as shown in Fig. 7 bottom detail.

Adhesion of the SAWR sensor to the test part is a critical step in the sensor preparation and performance for strain measurements, since the strain information is transferred to the sensor through the adhesive coupling layer. A cyanoacrylate-based adhesive was selected to attach both the commercial and the SAWR sensors to the beam (Fig. 7 bottom detail). The SAWR sensor was bonded to an Inconel coaxial cable via one mil thick pure Pt wires using a Unitek Unibond II resistance welder.

The commercial sensor response was recorded using a Vishay P3 strain indicator (Vishay Intertechnologies, Malvern, PA) connected in a quarter-bridge configuration [30] with the strain gauge (Fig. 7 middle detail). An Agilent E5071C VNA was used to interrogate the SAWR sensor, which relayed the frequency information to a host computer via GPIB interface. MATLAB (The MathWorks Inc., Natick, MA) data acquisition (DAQ) script collected the information from the VNA for data analysis. For the strain tests with the cyanoacrylate-based adhesive, nine precalibrated weights ranging between 10 grams and 250 grams were placed on a stainless steel platform attached to an $1 / 8$ inch diameter alumina rod to load the beam. Ten frequency sweeps were carried out at each weight. The test was repeated five times to verify that lateral friction or material accommodation were not significantly affecting the results.

\subsection{High-temperature Strain Testing Setup}

A block diagram of the high-temperature test setup and a picture of the assembly inside the furnace is shown in Fig. 8. A small 1/4 inch hole was drilled on the roof of the furnace and the alumina rod with loads placed outside the furnace lined up through it and above the loading location on the beam.

The difference in CTE between the LGS SAWR and Inconel pose a challenge for the sensor adhesion to the metallic beam at high-temperature. The CTE of LGS $\left(0^{\circ}, 138.5^{\circ}, 26.7^{\circ}\right)$ along the propagation direction is $\left(5 \mu \mathrm{m} / \mu \mathrm{m}^{\circ} \mathrm{C}\right)$, which is significantly different from that of Inconel $\left(13.5 \mu \mathrm{m} / \mu \mathrm{m}{ }^{\circ} \mathrm{C}\right)$. The room temperature cyanoacrylate-based adhesive used at room temperature is limited to $65^{\circ} \mathrm{C}$ for long-term operation as per manufacturer recommendation. Therefore, different high-temperature epoxies based on $\mathrm{Al}_{2} \mathrm{O}_{3}, \mathrm{MgO}$, $\mathrm{Mica}$, and $\mathrm{Ni}$ were tested for: (i) adequate adhesion to the LGS crystal and the Inconel part; (ii) maintenance of the LGS integrity; and (iii) consistency through cycling between room temperature and the testing temperature. $\mathrm{The} \mathrm{Al}_{2} \mathrm{O}_{3}$ based epoxy performed satisfactorily regarding adhesion requirements and thus was selected to attach the sensor to the beam.

The temperature compensation approach described in Section 4.1 was implemented using two SAWR sensors with identical design and from the same wafer. The strain sensor was rigidly attached to the beam surface using the $\mathrm{Al}_{2} \mathrm{O}_{3}$ ceramic epoxy, whereas the temperature sensor was loosely secured to the beam surface by $4 \mathrm{mil} \mathrm{Pt}$ wire bonding, allowing the device to slide at the surface of the beam (Fig. 8 detail), thus not responding to strain.

The presence of a finite layer of epoxy under the strain sensor delays the heat transfer from the metallic surface of the beam to the strain sensor LGS substrate. Therefore, a discrepancy in the temperature reading between the strain sensor and the temperature sensor arises. In order to mitigate this discrepancy in the temperature reading, the bottom surface of the temperature sensor was coated with a layer of epoxy and cured prior to placement on the beam surface. The strain and temperature sensors were mounted in close proximity to guarantee that the temperatures at both devices were very similar.

The sensor attached to the constant stress beam with the $\mathrm{Al}_{2} \mathrm{O}_{3}$ based epoxy was stress tested at room temperature to compare the results with the cyanoacrylate-based adhesive condition and verify the influence of the adhesive layer on the sensor response. Strain testing with the $\mathrm{Al}_{2} \mathrm{O}_{3}$ based epoxy was carried out using pre-calibrated 10, 20, 100, 150,200 , and 250 gram weights. The maximum value of the load applied was limited to avoid entering the plastic deformation or mechanical failure of the epoxy used to attach the sensor to the metallic beam under high-temperature operation. The tests were repeated five, six, and eight times at room temperature, $300^{\circ} \mathrm{C}$, and $400^{\circ} \mathrm{C}$, respectively, to 
check for data consistency. The tests were then averaged to mitigate the effect of experimental variations due to the loading of the rod, environmental variations, and equipment stability, such as the stability of the Agilent E5071C VNA, which is $\pm 0.05 \mathrm{ppm}[31]$ or a variation of $10 \mathrm{~Hz}$ at $195 \mathrm{MHz}$.

Additionally, signal processing and conditioning can contribute to improve the SAWR measurement precision at high-temperatures. As the temperature increases, the losses in the SAWR sensor increase [12], thus diminishing the device's quality factor, defined as $Q=f_{o} / \Delta f_{3 d B}$, where $f_{o}$ is the central frequency of the SAWR sensor and $\Delta f_{3 d B}$ is the $3 \mathrm{~dB}$ bandwidth. Figure 9 shows SAWR frequency responses at $24^{\circ} \mathrm{C}, 300^{\circ} \mathrm{C}$, and $400^{\circ} \mathrm{C}$, which reveal the decrease in quality factor measured in a $50 \Omega$ system from 54000 at $24^{\circ} \mathrm{C}$ to 6700 at $300^{\circ} \mathrm{C}$, and to 3600 at $400^{\circ} \mathrm{C}$. The $\mathrm{SAWR}$ impedance variation from room temperature to $400^{\circ} \mathrm{C}$ results in $53 \%$ variation in the magnitude of $\left|S_{11}\right|$ and broadening of the resonant peak, with $\Delta f_{3 d B}$ increasing more than 10 times as shown in Fig. 9. In addition, minute vibrations in the constant stress beam structure increase the noise in the measured $\left|S_{I I}\right|$ signal. In order to avoid deterioration of the precision and accuracy in tracking the peak of the sensor $\left|S_{11}\right|$ frequency response, data conditioning and signal processing are necessary. In this work, the measured SAWR $\left|S_{11}\right|$ data was post-processed in MATLAB using a Savitzky-Golay digital filter [32]. This polynomial-based filter is commonly used in applications that involve processing noisy signal to consistently retain the data peak shape and remove high frequency noise interference [33].

\section{Results and Discussion}

Strain sensor measurements reported in this section have been divided into three sub-sections with the respective rationale: (1) Comparison of the commercial sensor response with Abaqus predictions at room temperature, aiming at validating the FEM model based on experimental evidence; (2) Attachment at room temperature of the SAW strain sensor to the beam using both the cyanoacrylate-based adhesive and the high-temperature $\mathrm{Al}_{2} \mathrm{O}_{3}$-based epoxy, and comparison of the respective calibration curves; and (3) High-temperature SAWR strain sensor and temperature sensor measurements, and comparison with FEM model for the calibration of the SAWR strain measurements at hightemperatures.

\subsection{Comparison of Commercial Sensor and Abaqus Model}

Figure 10 compares measured strain data (squares connected by solid line) obtained from the room temperature commercial strain gauge and numerically calculated strain values using the FEM model (triangles connected by broken line) using the test setup described in Section 5.

The correlation coefficient $\left(R^{2}\right)$ between the simulated data and experimental data shown in Fig. 10 is approximately 0.999 . The confirmation that the FEM model correlates very well with commercial sensor measured data at room temperature served three purposes in this work: (i) Verify the consistency of the commercial sensor and the FEM numerical model; (ii) Allow the calibration the SAWR sensor at room temperature; and (iii) Validate the FEM model for usage as a reference for SAW strain calibration at high-temperatures, where no reliable commercial sensor is available.

\subsection{SAW Strain Sensor Attachment \& Calibration at Room Temperature: Cyanoacrylate-based Adhesive vs. High- temperature Epoxy}

\subsubsection{Attachment Using the Cyanoacrylate-based Adhesive}

Figure 11 shows the measured SAWR strained frequency shift with respect to no-strain $(\Delta f)$ on the constant stress beam as a function of strain measured with the commercial strain gauge at room temperature, using the test setup described in Section 5.1. In this experiment, the SAWR is attached to the beam using the cyanoacrylate-based adhesive. 
The error bars in the vertical and horizontal axes at each strain value represent the standard deviation for all the mean frequency shifts, and the standard deviation for the measured strain values, respectively between test repetitions. The linear regression analysis in Fig. 11 shows a $R^{2}$ of 0.999 and strain sensitivity of $-118 \mathrm{~Hz} / \mu \varepsilon$. The sensitivity of this sensor, calculated using the normalized frequency variation of the SAWR divided by the center frequency, $\Delta f / f_{o}$, is approximately $-0.60 \mathrm{ppm} / \mu \varepsilon$. This value of strain sensitivity is comparable to the SAWR strain sensitivity mentioned in [17] for AT-X quartz $(-0.55 \mathrm{ppm} / \mu \varepsilon)$, and somewhat lower than the SAW sensors strain sensitivities for YZ-LNO $(-1.8 \mathrm{ppm} / \mu \varepsilon)[5]$, LGS $\left(0^{\circ}, 138.5^{\circ}, 117^{\circ}\right)(-1.6 \mathrm{ppm} / \mu \varepsilon)[18]$, and AT-X Quartz $(-1.0 \mathrm{ppm} / \mu \varepsilon)[6]$.

\subsubsection{Attachment Using $\mathrm{Al}_{2} \mathrm{O}_{3}$-based Epoxy and Discussion}

Figure 12 shows the measured SAWR strained frequency shift with respect to no-strain $(\Delta f)$ at room temperature as a function of the strain response predicted by the FEM model (Fig. 6), using the test setup described in Section 5.2. In this case the $\mathrm{Al}_{2} \mathrm{O}_{3}$-based high-temperature epoxy was employed to attach the SAWR sensor to the constant stress beam. The usage of the Abaqus model in this case is justified due to the excellent correlation with the commercial sensor measurement, as verified in Section 6.1.

The error bars on the vertical axis at each strain value represent the standard deviation of all the measured mean frequency shifts of the SAWR between the test repetitions. The linear regression of the measured dataset shows $R^{2}$ of 0.999 , and strain sensitivity of $-52 \mathrm{~Hz} / \mu \varepsilon$.

Comparing the SAWR strain sensitivity values under the two mounting conditions, that is, when the SAWR was attached using the cyanoacrylate-based adhesive (Fig. 11) versus the $\mathrm{Al}_{2} \mathrm{O}_{3}$-based high-temperature epoxy (Fig. 12), one can note the first order relevance of the attachment method. The sensitivity of the sensor mounted using cyanoacrylate-based adhesive is more than twice as high as the sensor epoxied using the high-temperature epoxy. Assuming that the different attachment materials do not have a first order influence on the stress in the beam due to the small size of the sensors, the cyanoacrylate-based mounting transfers better the stress information from the constant stress beam to the sensor at room temperature. The reduction in the SAW strain sensor sensitivity when the $\mathrm{Al}_{2} \mathrm{O}_{3}$ based epoxy is used, is most likely due to a combination of the thicker epoxy film when compared to the cyanoacrylate-based adhesion film, and the compliance of epoxy material itself. Evidently, the distinct advantage of the $\mathrm{Al}_{2} \mathrm{O}_{3}$ based epoxy is to allow sensor operation at temperature above the $65^{\circ} \mathrm{C}$ limit of the cyanoacrylate-based adhesive.

\subsection{High-temperature Measurements}

Figures 13 and 14 show the measured SAW strained frequency shift with respect to no-strain $(\Delta f)$ as a function of the strain response predicted by the FEM model at $300^{\circ} \mathrm{C}$ and $400^{\circ} \mathrm{C}$ (Fig. 6), respectively. The vertical error bars at each strain value at both temperatures represent the standard deviation of all the measured mean frequency shifts of the SAWR for the several test repetitions.

Linear regression analyses reveal $R^{2}$ of 0.997 and sensitivity of $-44 \mathrm{~Hz} / \mu \varepsilon$ in Fig. 13 , and $R^{2}$, of 0.999 and sensitivity of $-41 \mathrm{~Hz} / \mu \varepsilon$ in Fig. 14. At around $11 \mu \varepsilon$, the high-temperature setup system reaches its noise level, with fluctuation in ambient and furnace temperature precluding a consistent sensor reading below that value. It should also be noted that as the temperature increases, the "no-strain condition" is affected by the difference in expansion coefficient between the SAWR substrate, the metallic constant stress beam, and the adhesive, thus creating a stress bias. This stress bias prevents consistent reading below a certain input level and also contributes to an increase in the measurement uncertainty. Figures 12, 13, and 14 reveal a decrease in the measured sensor sensitivity as the temperature is raised from room temperature to $400^{\circ} \mathrm{C}$. One possible explanation to this fact is the increase in the epoxy compliance property with temperature. In addition, for similar load excursions and cycling, the epoxy attachment degrade differently as temperature increases due to increasing levels of stress imposed by the difference in thermal expansion between the different materials. 
The temperature compensation scheme employed in this work enabled high-temperature strain measurements by reducing the temperature-strain cross-sensitivity effect of the LGS $\left(0^{\circ}, 138.5^{\circ}, 26.7^{\circ}\right)$ orientation. For the tested 0 to $114 \mu \varepsilon$ strain range the percentage reduction in uncertainty was calculated as

$$
100 * f \text { Strain }-f S f S \quad[\%]
$$

for each value of measured strain at both $300^{\circ} \mathrm{C}$ and $400^{\circ} \mathrm{C}$. Due to the temperature compensation scheme, the average reduction in frequency variation uncertainty considering all measured points at $300^{\circ} \mathrm{C}$ and $400^{\circ} \mathrm{C}$ was $40 \%$. It should also be noted that averaging over longer periods, when possible, is helpful in mitigating effects due the temperature transients. However, in real-time, in-situ strain measurements, long-period averaging may not be practical and temperature compensation schemes are more relevant. The implementation of the Savitzky-Golay filter reduced the root mean squared (RMS) noise of $\left|S_{I I}\right|$ around the SAWR frequency resonant peak up to 60 times for the data obtained at $300^{\circ} \mathrm{C}$ and $400^{\circ} \mathrm{C}$.

\section{Conclusions}

Static strain was directly measured from room temperature to up to $400^{\circ} \mathrm{C}$ using a SAWR sensor. In order to obtain the direct strain measurement, the SAWR frequency response sensor was calibrated using a FEM model developed for static strain on a constant stress beam. The FEM model was first verified against a commercial strain sensor at room temperature, and further extended for operation at high-temperature taking into consideration the variation of the stress beam material constants with temperature.

Sensor adhesives, packaging, signal conditioning, temperature compensation and the relevance of these topics for high-temperature SAWR sensor operation have been discussed. The results presented show that the high-temperature SAWR is a viable static strain sensor solution to fulfill the needs of relevant contemporary harsh-environment energy, aerospace, and industrial applications.

\section{Acknowledgment}

This work was supported by U.S. Department of Energy Award \#: DE-FE0007379TDD. Disclaimer: This report was prepared as an account of work sponsored by an agency of the United States Government. Neither the United States Government nor any agency thereof, nor any of their employees, makes any warranty, express or implied, or assumes any legal liability or responsibility for the accuracy, completeness, or usefulness of any information, apparatus, product, or process disclosed, or represents that its use would not infringe privately owned rights. Reference herein to any specific commercial product, process, or service by trade name, trademark, manufacturer, or otherwise does not necessarily constitute or imply its endorsement, recommendation, or favoring by the United States Government or any agency thereof. The views and opinions of authors expressed herein do not necessarily state or reflect those of the United States Government or any agency thereof.

\section{References}

[1] S. Basu, A. K. Debnath, Power Plant Instrumentation and Control Handbook, 1st ed. Academic Press, 2014.

[2] A. K. Elshennawy, G. S. Weheba, Manufacturing Processes and Materials, 5th ed. Dearborn, MI: SME, 2015.

[3] W.C. Wilson, M.D. Rogge, B.H. Fisher, D.C. Malocha, and G.M. Atkinson, "Fastener failure detection using a surface acoustic wave strain sensor," IEEE Sensors J., vol. 12, no. 6, pp. 1993-2000, Jun. 2012.

[4] J. Jia, X. Zhang, L, Cai, S, Zhang, Y. Tu, S. Tu, "Sensors for high-temperature displacement, deformation, and strain measurement: A review," Proc. Int. Conference of Structural Health Monitoring and Integrity Manage.,2014, pp. 25-32,. 
[5] J. Humphries and D. Malocha, "Wireless SAW Strain Sensor Using Orthogonal Frequency Coding", IEEE Sensors J., vol. 15, no. 10, pp. 5527-5534, Jun. 2015.

[6] B. Donohoe, D. Geraghty, G. E. O'Donnell, and R. Stoney, "Packaging considerations for a surface acoustic wave strain sensor," IEEE Sensors J., vol. 12, no. 5, pp. 922-925, May 2012.

[7] HITEC Products INC. Strain Gages for Static Strain Measurements. [Online]. Available: http://www.hitecprod.com/pages/static.html, [Accessed Dec. 2015].

[8] NASA, "High-Temperature Thin-Film Strain Gauges," NASA Glenn Research Center., Cleveland, OH, TOP300059, Dec. 2007.

[9] J. Huang, Z. Zhou, D. Zhang and Q. Wei, "A Fiber Bragg Grating Pressure Sensor and Its Application to Pipeline Leakage Detection", Advances in Mechanical Engineering, vol. 5, no. 5, pp. 1-6, Jun. 2013.

[10] X. Jiang, K. Kim, S. Zhang, J. Johnson and G. Salazar, "High-Temperature Piezoelectric Sensing", Sensors, vol. 14, no. 1, pp. 144-169, Dec. 2013.

[11] Q. Tan, C. Li, J. Xiong, P. Jia, W. Zhang, J. Liu, C. Xue, Y. Hong, Z. Ren and T. Luo, "A High Temperature Capacitive Pressure Sensor Based on Alumina Ceramic for in Situ Measurement at $600{ }^{\circ} \mathrm{C}$,Sensors, vol. 14, no. 2, pp. 2417-2430, Jan. 2014.

[12] M. Pereira da Cunha, "Wireless sensing in hostile environments", Proc. IEEE Int'l Ultrason. Symp., 2013, pp. 1337-1346.

[13] T. M. Reeder, D. E. Cullen, and M. Gilden, "SAW oscillator pressure sensor," IEEE Ultrasonics. Symp. Proc., 1975, pp. 264-268.

[14] B. Dixon, V. Kalinin, J. Beckley, and R. Lohr, "A second generation in-car tire pressure monitoring system based on wireless passive saw sensors," in Proc. 2006 IEEE Int. Frequency Control Symp., Expo., June 2006, pp. 374380 .

[15] V. Kalinin, "Wireless physical SAW sensors for automotive applications", IEEE Int'l Ultrasonics Symp., 2011, pp. 212-221.

[16] Environetix, "Wireless Sensor System in Harsh Environment « Environetix Technologies Corporation - Wireless High Temperature Harsh Environment Sensors". [Online]. Available: http://www.environetix.com/technologiessolutions/wireless-sensor system-in-harsh-environment, [Accessed Dec. 2015].

[17] B. Donohoe, D. Geraghty, and G. E. O'Donnell, "Wireless calibration of a surface acoustic wave resonator as a strain sensor," IEEE Sensors J., vol. 11, no. 4, pp. 1026-1032, Apr. 2011.

[18] L. Shu, B. Peng, Z. Yang, R. Wang, S. Deng and X. Liu, "High-Temperature SAW Wireless Strain Sensor with Langasite", Sensors, vol. 15, no. 11, pp. 28531-28542, Nov. 2015.

[19] M. Pereira da Cunha, R.J. Lad, T. Moonlight, S. Moulzolf, A. Canabal, R. Behanan, P. M. Davulis, D. Frankel, G. Bernhardt, T. Pollard, D. F. McCann, "Recent Advances in Harsh Environment Acoustic Wave Sensors for Contemporary Applications," Proc. of 2011 IEEE Sensors, 2011, pp. 614-617.

[20] M. Pereira da Cunha, R. J. Lad, T. Moonlight, G. Bernhardt, and D. J. Frankel, "High temperature stability of langasite surface acoustic wave devices," Proc. IEEE Int'l Ultrason. Symp., 2008, pp. 205-208.

[21] D. J. Frankel, G. P. Bernhardt, B. T. Sturtevant, T. Moonlight, M. Pereira da Cunha, and R. J. Lad, "Stable electrodes and ultrathin passivation coatings for high temperature sensors in harsh environments," Proc. IEEE Sensors, 2008, pp. 82-85.

[22] S. Moulzolf, D. Frankel, M. Pereira da Cunha and R. Lad, "High temperature stability of electrically conductive $\mathrm{Pt}-\mathrm{Rh} / \mathrm{ZrO} 2$ and $\mathrm{Pt}-\mathrm{Rh} / \mathrm{HfO} 2$ nanocomposite thin film electrodes", Microsystem Technologies, vol. 20, no. 4-5, pp. 523-531, 2013

[23] M. Pereira da Cunha, A. Maskay, R. J. Lad, D. J. Frankel, S. Moulzolf, M. Call, G. Bernhardt, and, "Pt-Ni / Pt-Zr Electrodes for Stable SAW Resonator Operation During Repeated Temperature Cycling up to $1000^{\circ} \mathrm{C}$," Proc. IEEE Int'l Ultrason. Symp., 2015, pp. 1-4.

[24] S. C. Moulzolf, R. Behanan, R. J. Lad, M. P. da Cunha, "Langasite SAW Pressure Sensor for Harsh Environments," Proc. IEEE Ultrasonics Symposium, 2012, pp. 1224-1227. 
[25] M. Pereira da Cunha and S. de Azevedo Fagundes, "Investigation on recent quartz-like materials for SAW applications", IEEE Transactions on Ultrasonics, Ferroelectrics and Frequency Control, vol. 46, no. 6, pp. 15831590, Nov. 1999.

[26] ASTM Standard E251-92, (2014), "Standard Test Methods for Performance Characteristics of Metallic Bonded Resistance Strain Gauges," ASTM International, West Conshohocken, PA, 2006, DOI: 10.1520/E025192R14, www.astm.org.

[27] M. Vable, Mechanics of Materials, 2nd ed. Houghton, MI: MTU, 2012, ch. 7, pp. 332-333.

[28] Special Metals. INCONEL alloy 625LCF. [Online]. Available: http://www.specialmetals.com/assets/documents/alloys/inconel/inconel-alloy-625lcf.pdf, [Accessed Dec. 2015].

[29] Micro-Measurements. General Purpose Strain Gages - Linear Pattern. [Online]. Available: http://www.vishaypg.com/docs/11075/032uw.pdf, [Accessed Dec. 2015].

[30] Micro-Measurements. Application Note [Online]. TT-612. Available: http://www.vishaypg.com/docs/11092/tt612.pdf, [Accessed Dec. 2015].

[31] Keysight Technologies. E5071C ENA Network Analyzer. [Online]. Available: http://cp.literature.agilent.com/litweb/pdf/5989-5479EN.pdf, [Accessed Dec. 2015].

[32] R. Schafer, "What Is a Savitzky-Golay Filter? [Lecture Notes]", IEEE Signal Process. Mag., vol. 28, no. 4, pp. 111-117, Jul. 2011.

[33] C. Candan and H. Inan, "A unified framework for derivation and implentation of Savitzky-Golay filters", Signal Process. Journal, vol. 104, pp. 203-211, Nov. 2014. 


\section{Figure Captions}

Fig. 1. Photograph of a SAWR sensor with a micrograph depicting the electrode pattern of the SAWR sensor.

Fig. 2. Illustration: constant stress beam diagram.

Fig. 3. Inconel-625 constant stress beam used and FEM verification of constant stress operation.

Fig. 4. Measured (discrete points) and interpolated (straight curve) SAWR frequency variation vs. temperature variation.

Fig. 5. Temperature dependency of Inconel-625 mechanical constants: (a) Fractional variations of Young modulus $(\Delta \% \mathrm{Y})$, left axis; and Poisson ratio $(\Delta \% v)$, right axis; (b) CTE $(\alpha)$. Discrete points [28] and interpolated curves (see text).

Fig.6. Simulated strain as a function of load mass extracted at $24^{\circ} \mathrm{C}, 300^{\circ} \mathrm{C}$, and $400^{\circ} \mathrm{C}$ using the FEM model.

Fig. 7. Block Diagram (top) and photograph (bottom) of room temperature test setup (sensors attached by cyanoacrylate-based adhesive).

Fig. 8. Block Diagram (top) and photograph (bottom) of high temperature test setup (rigidly attached strain sensor using $\mathrm{Al}_{2} \mathrm{O}_{3}$-based epoxy; temperature sensor held using 4 mil thick Pt wires that allows device to slide at the surface of the beam).

Fig. 9. SAWR strain sensor frequency spectra around the resonant peak measured at $24^{\circ} \mathrm{C}, 300^{\circ} \mathrm{C}$, and $400^{\circ} \mathrm{C}$, illustrating the effect of decreasing quality factor in sensor response as the temperature increases.

Fig. 10. Validation of FEM model at room temperature by comparing experimental (commercial strain gauge, squares connected by solid line) and simulated strain (FEM model, triangles connected by broken line).

Fig. 11. Measured SAWR frequency variation (vertical axis) vs. measured Vishay strain gage (horizontal axis) carried out at $24^{\circ} \mathrm{C}$ using the cyanoacrylate based adhesive (unstrained SAWR resonant frequency, $f_{o}=195.8 \mathrm{MHz}$ ).

Fig. 12. Measured SAWR frequency variation vs. FEM predicted strain response at $24^{\circ} \mathrm{C}$ using $\mathrm{Al}_{2} \mathrm{O}_{3}$ based epoxy (unstrained SAWR resonant frequency, $f_{o}=195.2 \mathrm{MHz}$ ).

Fig. 13. Measured SAWR frequency variation vs. FEM predicted strain response at $300^{\circ} \mathrm{C}$ using $\mathrm{Al}_{2} \mathrm{O}_{3}$ based epoxy (unstrained SAWR resonant frequency, $f_{o}=194.3 \mathrm{MHz}$ ).

Fig. 14. Measured SAW frequency variation vs. FEM predicted strain response at $400^{\circ} \mathrm{C}$ using $\mathrm{Al}_{2} \mathrm{O}_{3}$ based epoxy (unstrained SAWR resonant frequency, $f_{o}=193.6 \mathrm{MHz}$ ). 


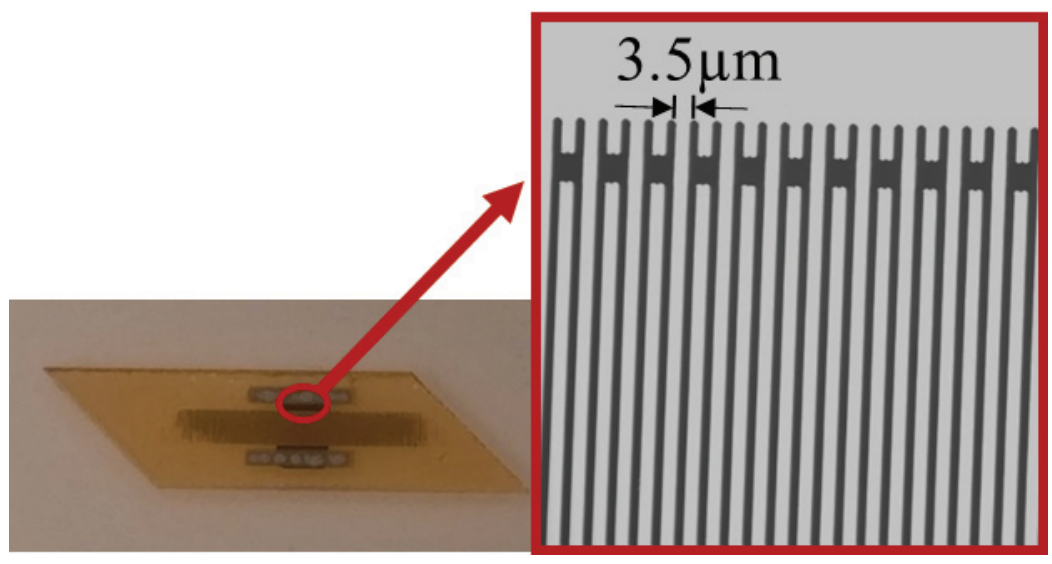

Fig. 1. Photograph of a SAWR sensor with a micrograph depicting the electrode pattern of the SAWR sensor.

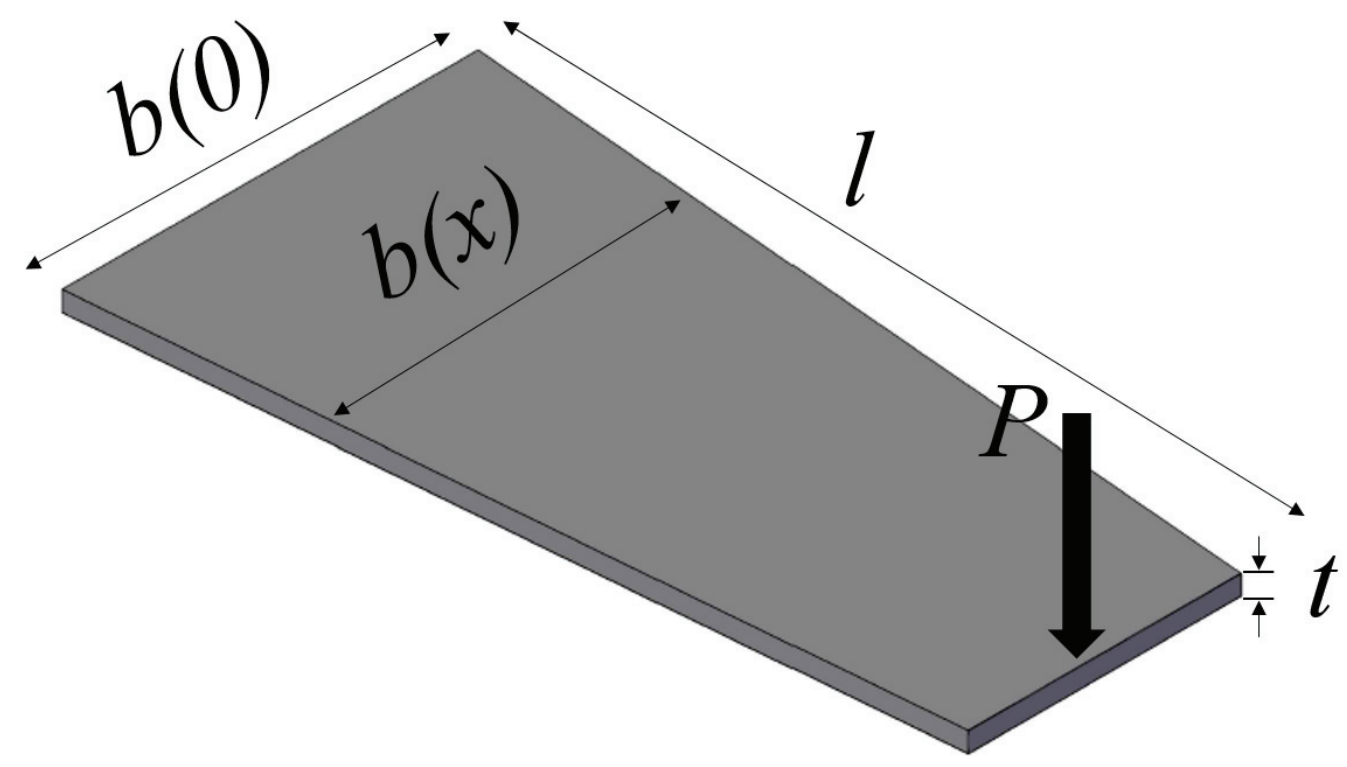

Fig. 2. Illustration: constant stress beam diagram. 

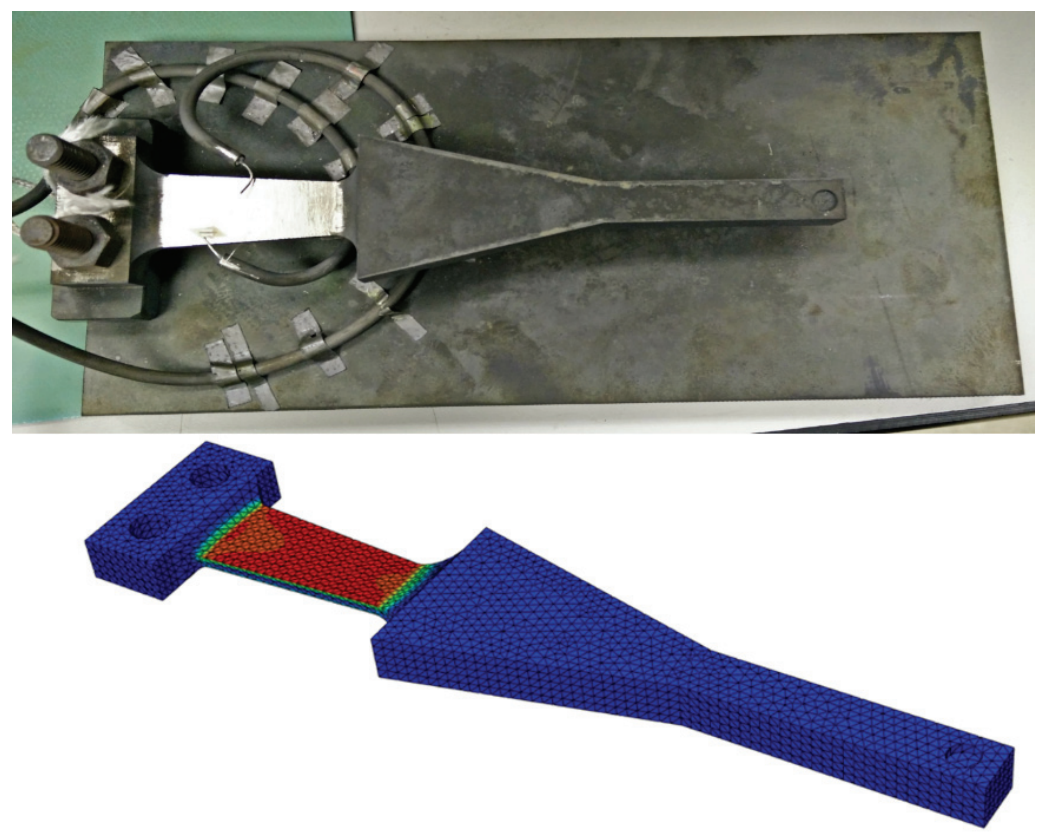

Fig. 3. Inconel-625 constant stress beam used and FEM verification of constant stress operation.

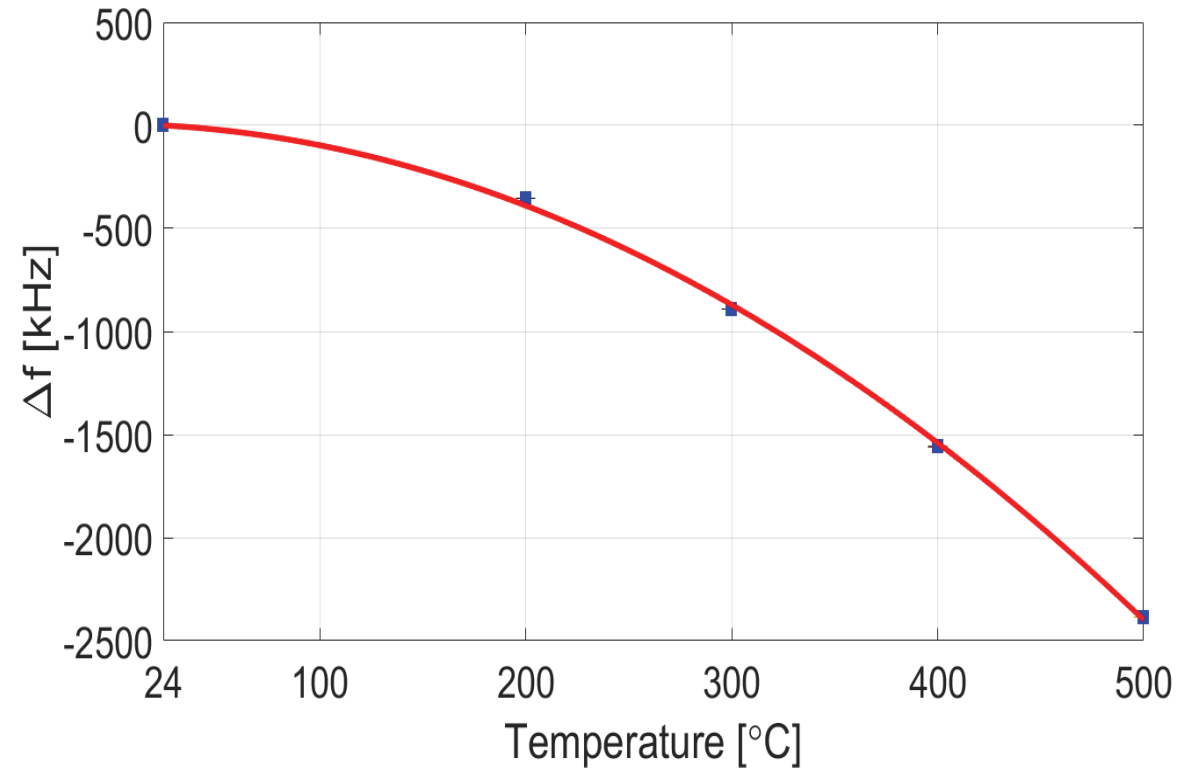

Fig. 4. Measured (discrete points) and interpolated (straight curve) SAWR frequency variation vs. temperature variation. 

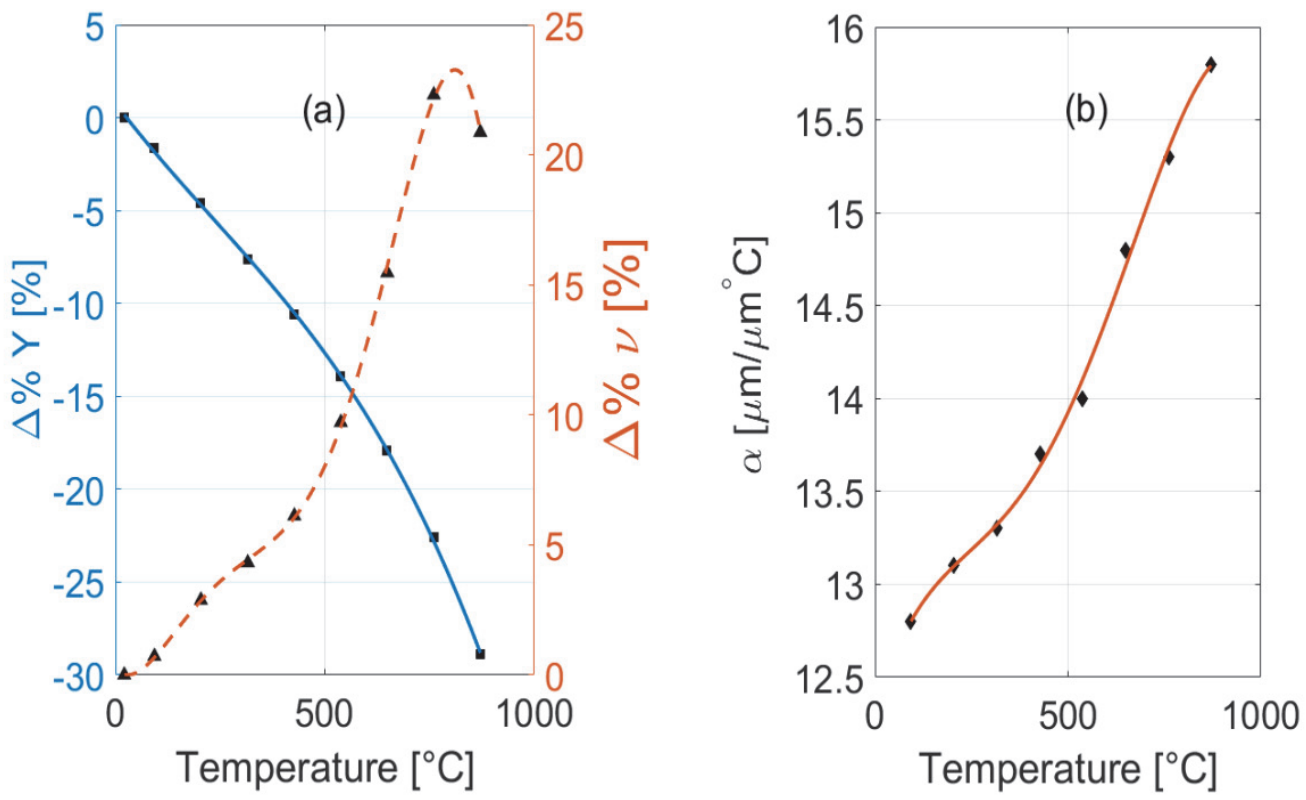

Fig. 5. Temperature dependency of Inconel-625 mechanical constants: (a) Fractional variations of Young modulus $(\Delta \% \mathrm{Y})$, left axis; and Poisson ratio $(\Delta \% v)$, right axis; (b) CTE $(\alpha)$. Discrete points [28] and interpolated curves (see text).

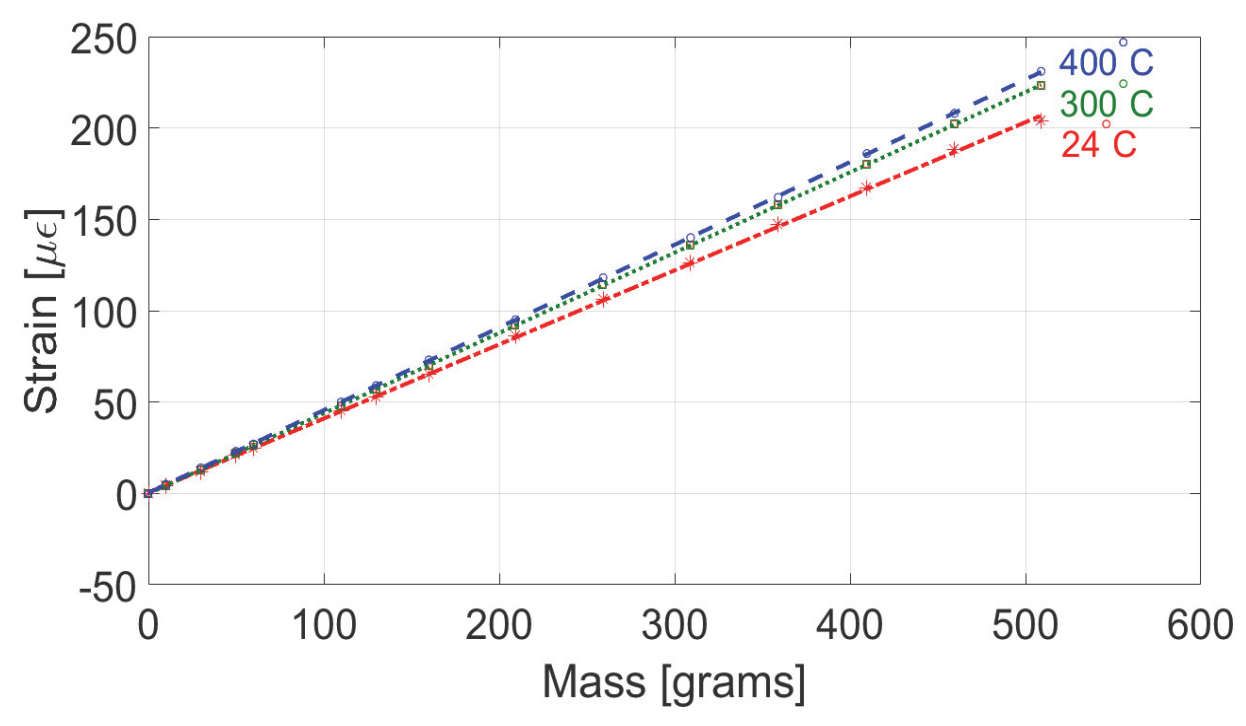

Fig. 6. Simulated strain as a function of load mass extracted at $24^{\circ} \mathrm{C}, 300^{\circ} \mathrm{C}$, and $400^{\circ} \mathrm{C}$ using the FEM model. 


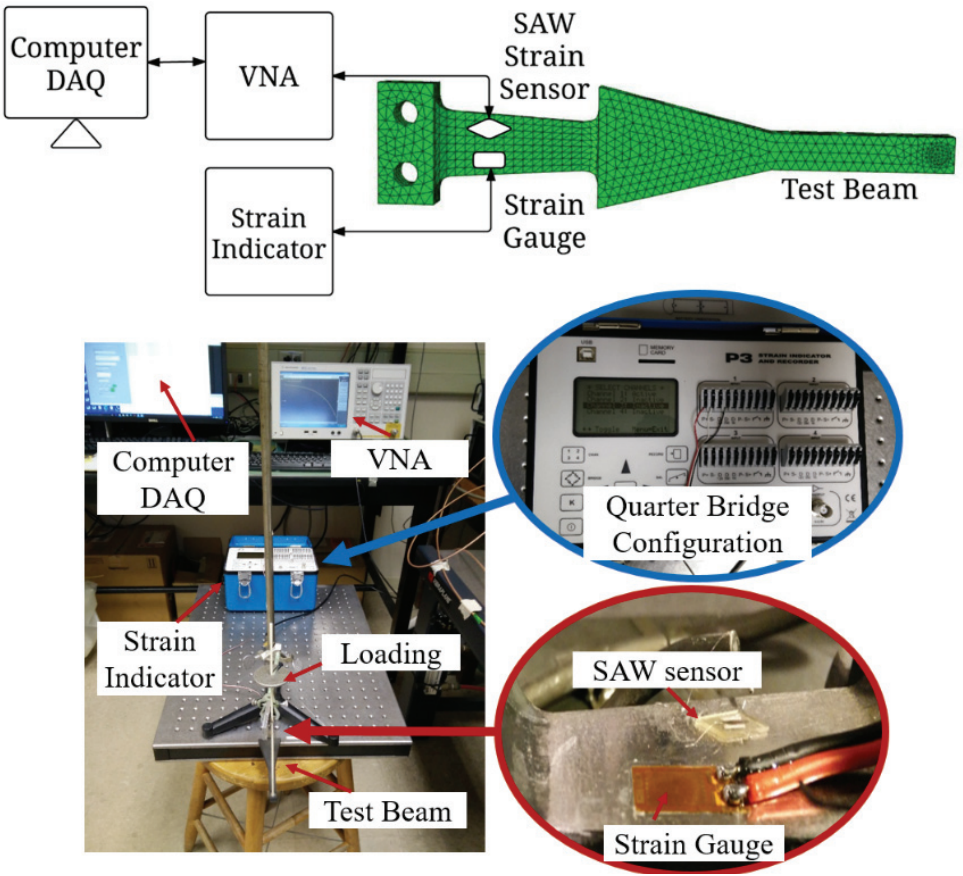

Fig. 7. Block Diagram (top) and photograph (bottom) of room temperature test setup (sensors attached by cyanoacrylate-based adhesive).

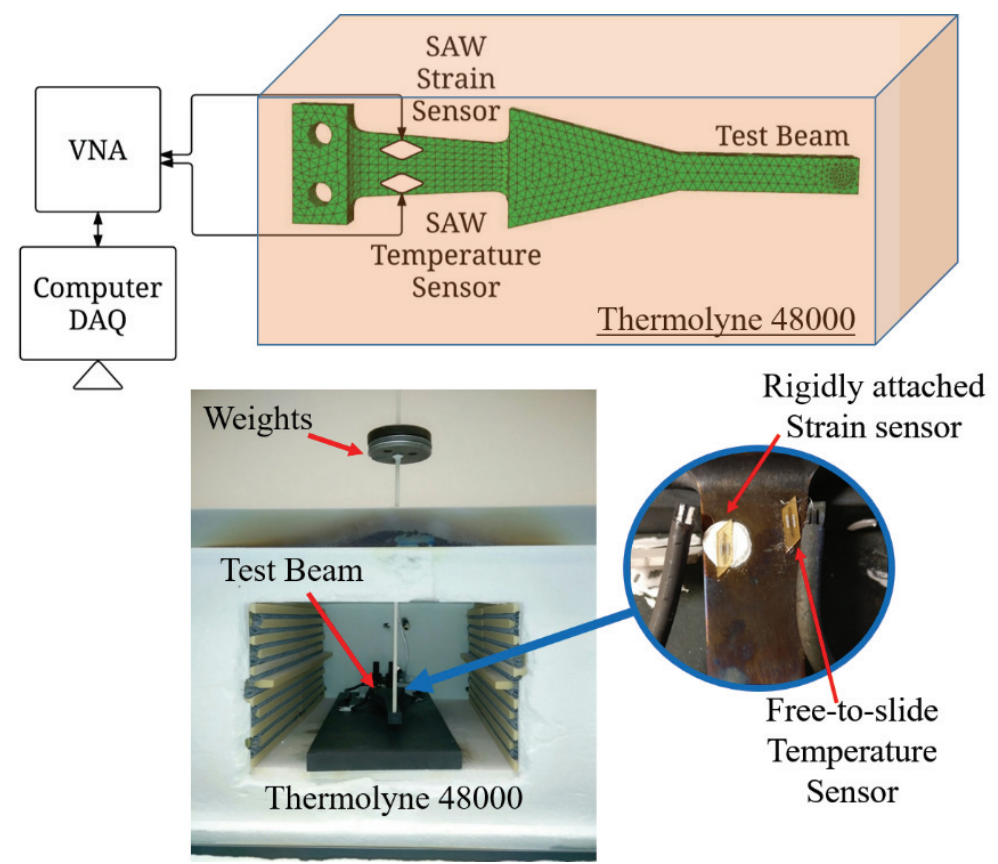

Fig. 8. Block Diagram (top) and photograph (bottom) of high temperature test setup (rigidly attached strain sensor using $\mathrm{Al}_{2} \mathrm{O}_{3}$-based epoxy; temperature sensor held using 4 mil thick Pt wires that allows device to slide at the surface of the beam). 

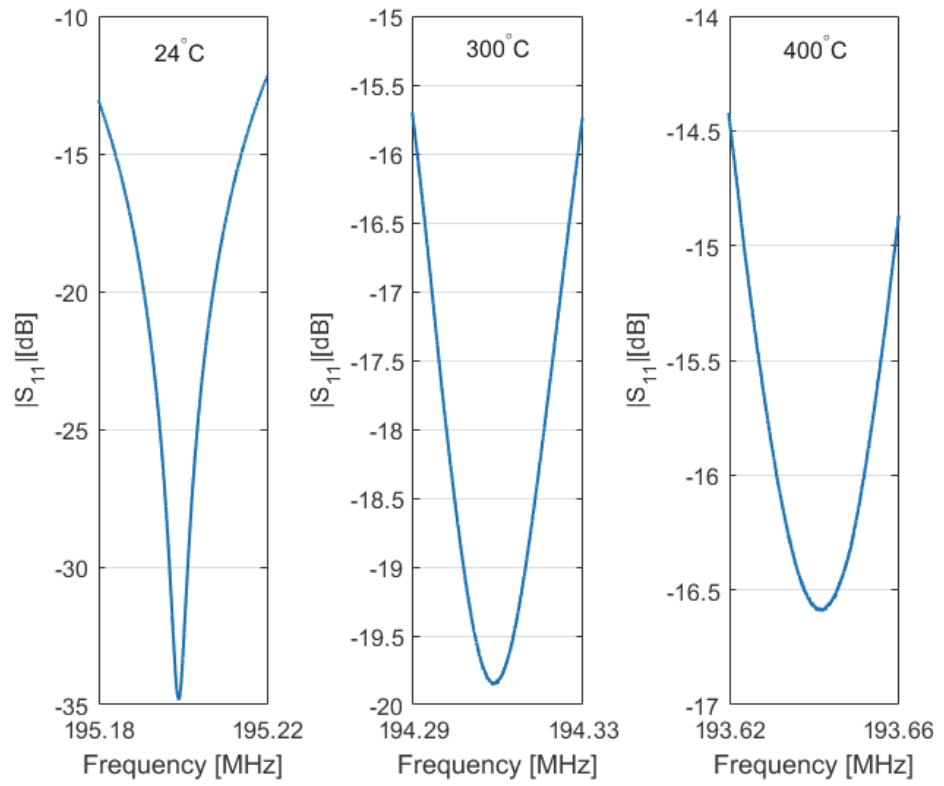

Fig. 9. SAWR strain sensor frequency spectra around the resonant peak measured at $24^{\circ} \mathrm{C}, 300^{\circ} \mathrm{C}$, and $400^{\circ} \mathrm{C}$, illustrating the effect of decreasing quality factor in sensor response as the temperature increases.

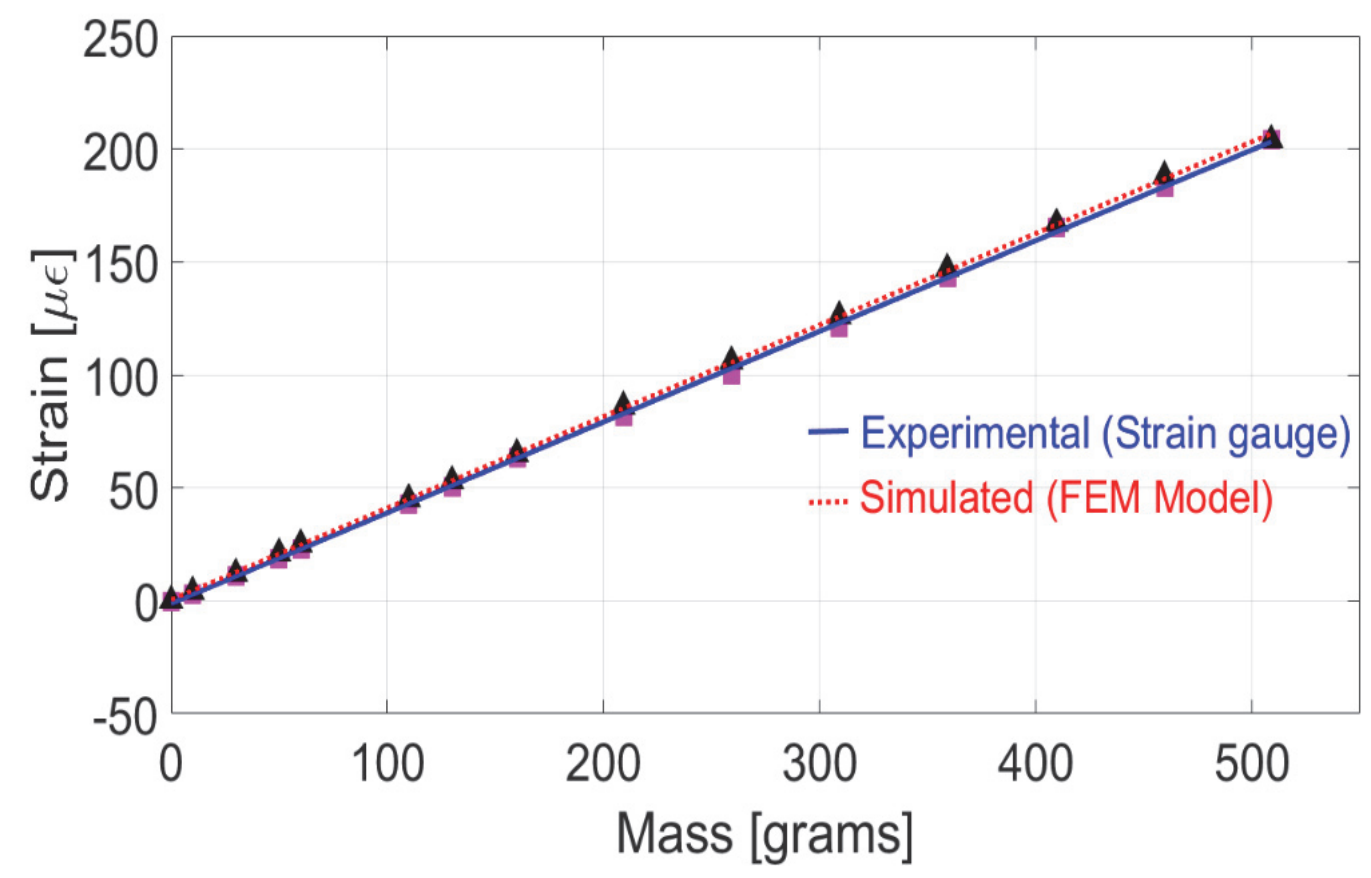

Fig. 10. Validation of FEM model at room temperature by comparing experimental (commercial strain gauge, squares connected by solid line) and simulated strain (FEM model, triangles connected by broken line). 


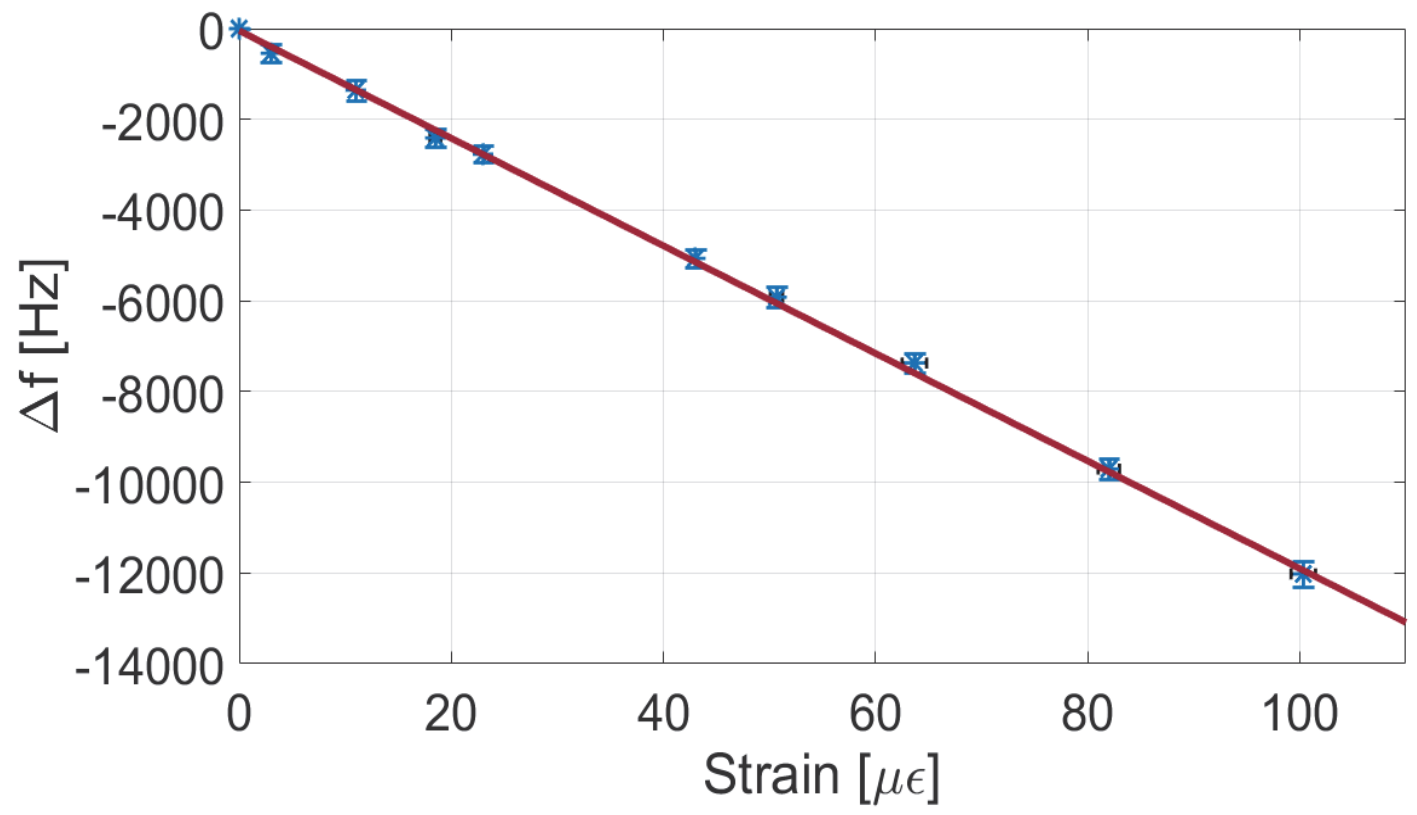

Fig. 11. Measured SAWR frequency variation (vertical axis) vs. measured Vishay strain gage (horizontal axis) carried out at $24^{\circ} \mathrm{C}$ using the cyanoacrylate based adhesive (unstrained SAWR resonant frequency, $f_{o}=195.8 \mathrm{MHz}$ ).

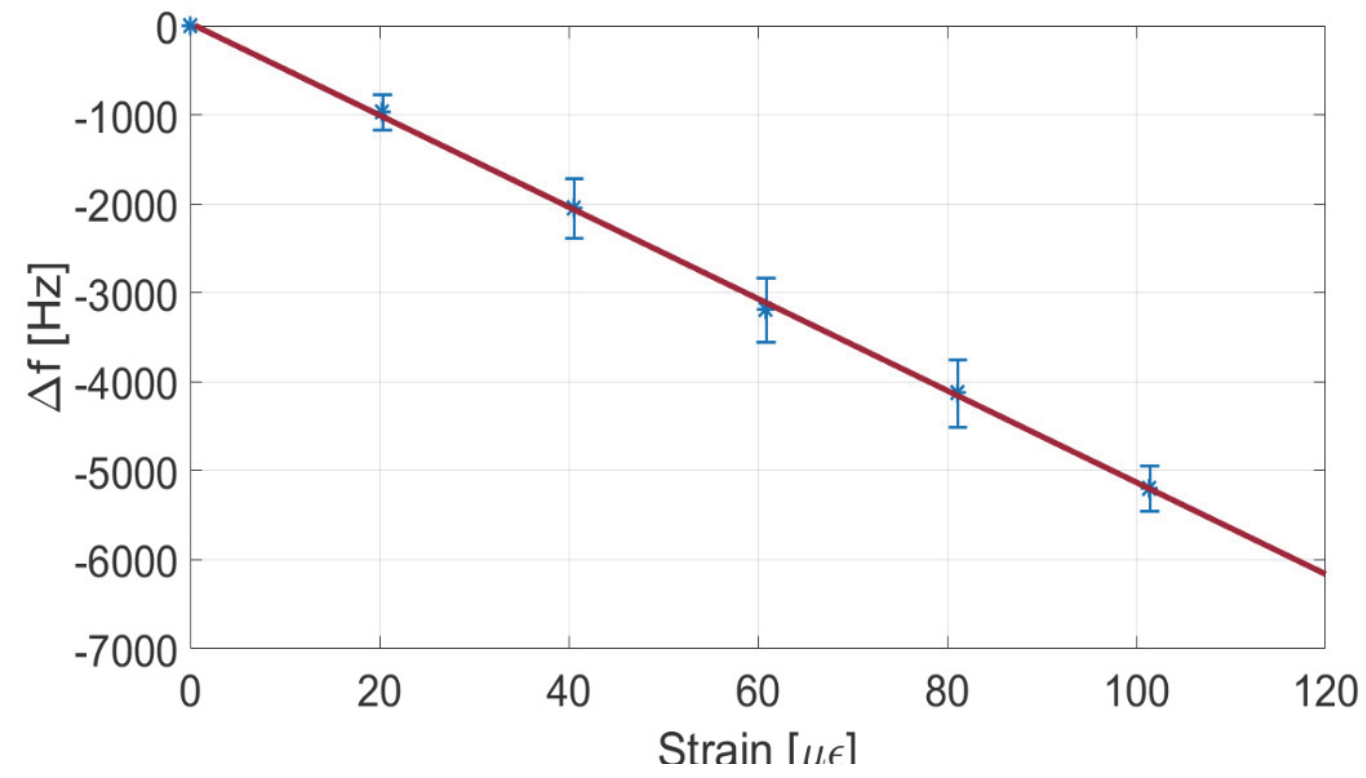

Fig. 12. Measured SAWR frequency variation vs. FEM predicted strain response at $24^{\circ} \mathrm{C}$ using $\mathrm{Al}_{2} \mathrm{O}_{3}$ based epoxy (unstrained SAWR resonant frequency, $f_{o}=195.2 \mathrm{MHz}$ ). 


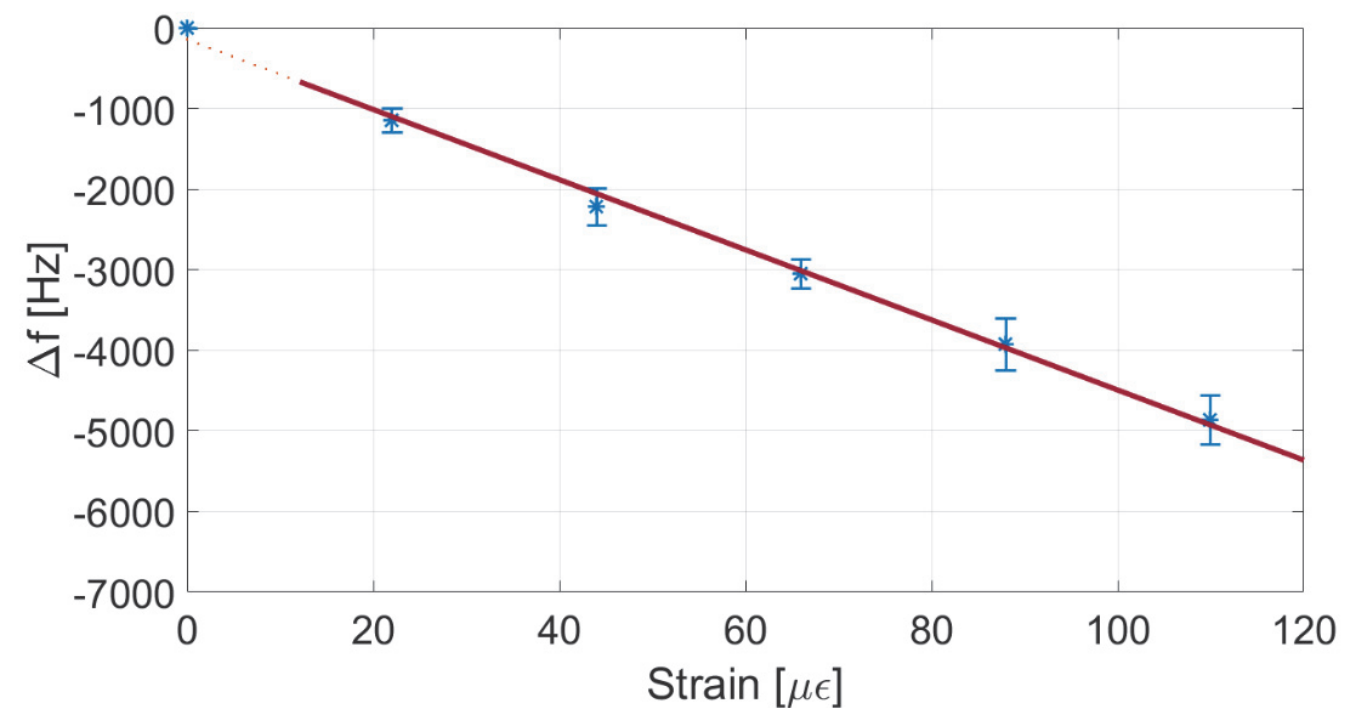

Fig. 13. Measured SAWR frequency variation vs. FEM predicted strain response at $300^{\circ} \mathrm{C}$ using $\mathrm{Al}_{2} \mathrm{O}_{3}$ based epoxy (unstrained SAWR resonant frequency, $f_{o}=194.3 \mathrm{MHz}$ ).

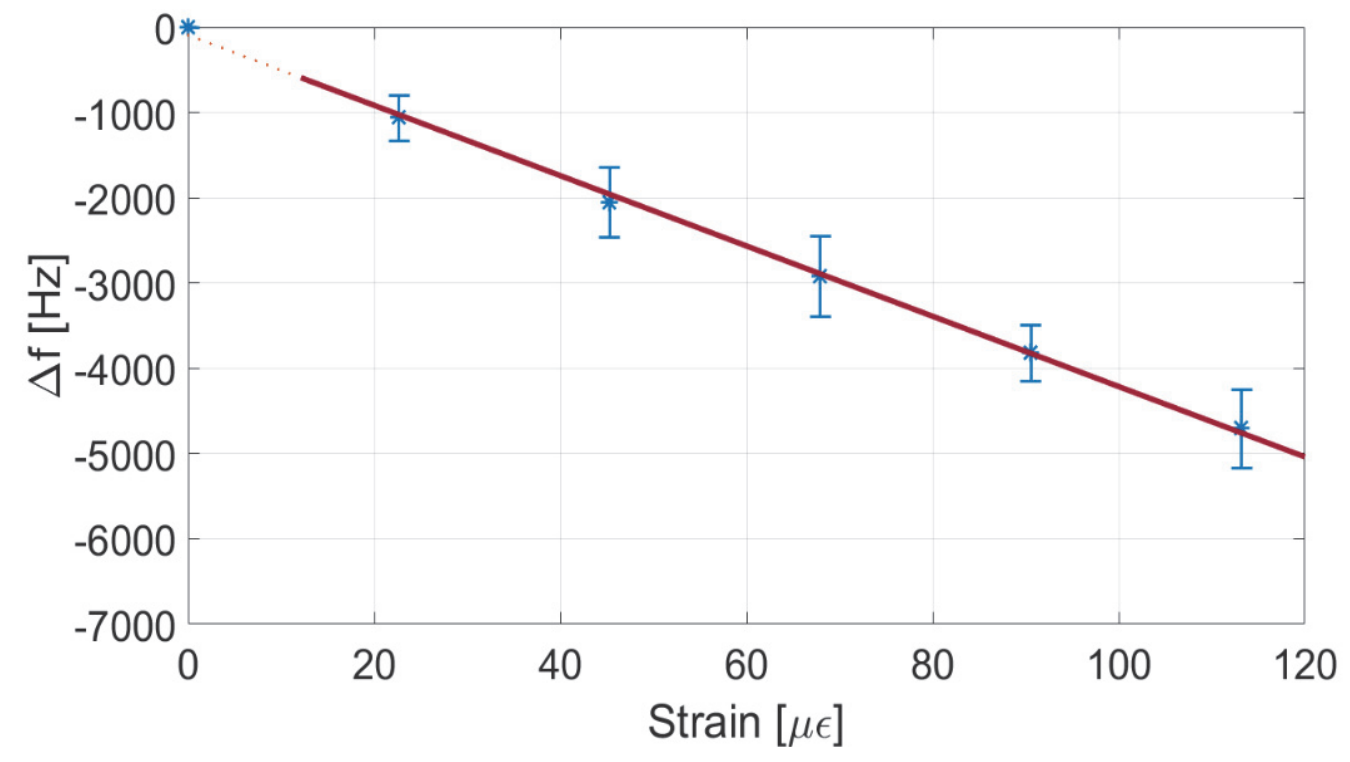

Fig. 14. Measured SAW frequency variation vs. FEM predicted strain response at $400^{\circ} \mathrm{C}$ using $\mathrm{Al}_{2} \mathrm{O}_{3}$ based epoxy (unstrained SAWR resonant frequency, $f_{o}=193.6 \mathrm{MHz}$ ). 